\title{
Students' Acceptance of Discord as an Alternative Online Learning Media
}

\author{
https://doi.org/10.3991/ijet.v16i20.22917
}

\author{
Muhammad Lukman Arifianto $\left({ }^{\bowtie}\right)$, Iqbal Fathi Izzudin \\ Universitas Negeri Malang, Malang, Indonesia \\ muhammad.arifianto.fseum.ac.id
}

\begin{abstract}
Since the public release of Discord in May 2015, gamers have widely used it as an additional team speak application to communicate with their teammates while playing games. However, with substantial features, this application is also used as an alternative media of communication in teaching and learning activities. Therefore, this study aims to determine students' acceptance of Discord as alternative teaching and learning media. Data were obtained using a simple questionnaire. Furthermore, their experience and acceptance towards this application are explored using the technology acceptance model (TAM) framework. The result showed that most participants confirmed that Discord is a favorable alternative media due to the attractive user interface, completeness of features, and its ease of use. Therefore, this application, which was originally intended for the gaming team-speak and team-chat experiences, can surprisingly be used as an alternative online learning media, especially during the Covid-19 pandemic, and it is well accepted by most students.
\end{abstract}

Keywords—discord, gamification, learning medium, Technology Acceptance Model (TAM)

\section{Introduction}

The Covid-19 pandemic, which was first recorded in Indonesia at the end of February 2020 , led to the mandatory use of information technology by various parties to carry out their daily activities [1][2][3][4]. In a bid to stop the spread of the virus, the government implemented laws prohibiting social gatherings, such as school activities, campuses, offices, music concerts, visits to culinary centers, shopping, etc. Furthermore, the government launched the Work from Home (WFH) and School from Home (SFH) program to overcome and reduce the spread of Covid-19 infections, thereby shifting activities from face-to-face to online-based [5]. Therefore, this led to the increase in the dependence of people on the availability of a good and stable Internet connection $[5][6][7]$. The data shows that the use of the Internet during this pandemic has increased significantly [8].

The pandemic has completely changed the learning activities in almost all educational institutions globally, from face-to-face classrooms into virtual spaces [9]. Some of the online media selected by the instructors for their virtual classes are WhatsApp, 
Zoom, Google Meet Big Blue Button, and a couple of learning management systems such as Google Classroom and Edmodo [10][11][12].

However, there are some inconsistencies associated with the use of these applications in carrying out online learning. Some of the obstacles are the technical constraints on the use of learning media, such as unsupported devices, slow internet connection, and others. According to studies, a good number of learning media used for educational purposes have a less attractive user interface, which makes students feel bored and unenthusiastic in participating in educational activities [9]. Furthermore, some of these applications lack features on the media intended for learning activities. For instance, the frequently used media such as Zoom and Google Meet are only limited to providing video and audio calling services and screen-sharing activities, despite the availability of online chat features in these applications. Therefore, teachers and students need another separate application for daily communication.

Another obstacle experienced by students in online learning is the large use of Internet quota due to the use of media that offers video conferencing services. This is generally the main problem experienced by students whose parents have low income due to its impact on increasing family expenses [13][14]. Therefore, these obstacles encouraged the authors to seek alternative applications that are more quota-friendly with sufficient video and audio quality to support the teaching and learning activities.

One of such applications is Discord, which is simply a chat platform comprising of text, voice, and video features [15][16][17]. This application is easily used in a web browser, such as a desktop or mobile application. It was created and -significantly used by the gamer community, therefore, the Discord icon represents a game controller [17]. This application currently hosts servers on various occasions by enabling users to create a profile and join a community based on their interests. The word server in this context is a collection of persistent chat rooms and voice channels.

According to Razell [18], many students at the University of Victoria used Discord to stay connected to each other during the Covid-19 outbreak. Through this application, they were able to exchange information on learning materials, exams, and lecture assignments, as well as share a variety of knowledge regarding life outside campus, such as music, films, food, hobbies, etc.

The use of Discord as one of the learning media is called gamification. This term is defined as using in-game elements, gameplay, aesthetics, environments, and mindsets to motivate students [19][20]. It is also defined as the use of game elements focused on engaging students digitally, using digital platforms or applications such as tablets, smartphones, or computers. This aims to increase motivation and enthusiasm for students learning activities by using the new learning media related to gaming, which is already familiar among them [21].

As an application originally devoted to supporting online games, Discord is now surprisingly used as a communication medium for learning purposes. The use of this application in the learning activities is expected to increase the interest and enthusiasm of students. Since it was originally intended for gamers to communicate, strategize, and have fun while playing games, hopefully, students can also do the same things during their learning process. Equipped with more complete features than Google Meet and 
Zoom and the use of less internet quota, Discord has the potential to become a favorable online learning application, both as the conversation and video conference media.

\subsection{Previous Studies}

Numerous studies have attempted to explain the use of Discord as a learning medium. For instance, Wulanjani [22] explored its use and stated that the Discord application makes classroom learners more active, interactive, and motivated. Therefore, Wulanjani stated that Discord has the ability to change from a conventionalmonotonous listening class to a virtually attractive class. However, the findings were obtained from the results of interviews with some class members, without mapping the acceptance of all students as an alternative learning media.

Meanwhile, Cacho [23] analyzed the potential use of Discord to improve student communication, engagement, and performance by measuring their response as an optional component to the class. Cacho found that $80.9 \%$ of the students believed that their grades improved due to the use of the application. In this study, a total of 23 questions were asked, and among the responses, $98.5 \%$ of all the students stated that they enjoyed Discord and would be pleased to see it implemented in future classes. The research conducted by Cacho is similar to this study, which focuses on students' perspectives on usage only, while the ease of access and comparisons with other similar applications have not been fully discussed.

Jiang et al. [24] observed the moderation challenges in voice-based online communities on Discord. In this research, Jiang used moderate practices in the context of realtime, voice-based communication with 25 in-depth interviews. Based on the observation, it was found that the affordances of voice-based online communities changed the process of moderating content and interactions. For instance, it provides new ways to break rules that moderators of text-based communities find unfamiliar, such as disruptive noise and voice raiding. However, acquiring evidence of rule-breaking behaviors was difficult due to the ephemerality of real-time voice. Meanwhile, moderators have developed new strategies, which are limited and often based on hearsay and first impressions, leading to problems ranging from unsuccessful moderation to false accusations. This study does not discuss the perspective or acceptance of participants towards the use of the application, therefore, it needs to be explored more deeply.

Lacher \& Biehl [25] researched the use of Discord to moderate students' collaboration and teamwork. Based on their experience, this application can be used to facilitate group work and monitor or track their activity. Furthermore, it can also be used by instructors to moderate group interactions and also send messages to students. Instructors tend to create Discord servers, which act as virtual classrooms and activate group chat rooms which are used to determine the strategies used by students to perform tasks and their level of participation. The first objective of the Discord implementation project is to introduce a user-friendly tool that instructors can use to moderate group interactions and observe students' participation. The second objective is to maximize the ability to access programmed group communication of students to determine the effectiveness of their performance. However, studies have not been conducted to observe the use of Discord from the user experience, perception, and acceptance point of view. 
Kruglyk et al. [26] showed the features of using Discord to create a quality remote communication environment during emergency learning. Kruglyk et al. stated that modern distance learning systems are not well developed for use in emergencies. Therefore, to solve this problem, a comparative analysis of distance communication tools regarding features and capabilities regarding the introduction of remote learning communication servers was conducted. This analysis determined Discord as a platform for communication environment during distance learning during the global pandemic. However, they failed to discuss students' perceptions or acceptance towards the use of the application.

\subsection{Technology Acceptance Model (TAM)}

Perception plays a significant role in students' successful learning abilities. Therefore, this study investigates students' perceptions of using the Discord application as an alternative learning medium during the Covid-19 pandemic. It measures students' perception of the product using the technology acceptance model (TAM).

According to [27], TAM is the main model used to explain the strategies utilized by students in adopting and using technology [27]. This TAM was developed based on the Theory of Reasoned Action (TRA) proposed by Fishbein and Ajzen [28]. It explains the user's perceived usefulness (PU) and perceived ease of use (PEOU) as factors that influence their decisions to adopt and use new technology. Usability is defined as the extent to which users believe that certain technology aid to improve their performance.

TAM has been used extensively in examining how students adopt learning technology in the classroom based on its usefulness and ease of use [29]. Students would generally feel the need to use a particular learning technology, assuming it is easy to use [30][31]. Some studies have shown a positive relationship between perceived benefits and intentions to be used to adopt learning technology in the classroom. For example, Larmuseau et al. [32] found that students' perceptions of teaching quality significantly positively affected their acceptance rates. In addition, their perceptions have a positive effect on the quality and not the quantity of usage. Meanwhile, students' acceptance of the online learning environment has no impact on usage. Another study conducted by Chung and Ackerman [33] in explaining students' reactions to Moodle classroom management software stated that they positively perceive it due to its positive benefits in their educational progress. In this study, communication was tagged as the usability factor needed by students. Moreover, Al-Maroof et al. [34] stated that perceived ease of use and perceived usefulness essentially affect the utilize learning technology. Furthermore, perceived of usefulness is fundamentally affected by the perceived of ease of use and user experience.

The various studies conducted by previous scholars noted that students' acceptance of Discord as an alternative online learning media within the Technology Acceptance Model (TAM) framework has never been closely studied. Therefore, this topic still needs adequate attention to be elaborated. The research on the use of instructional media applications should not be limited to the learning process alone. Therefore, it needs 
to include discussions regarding user's acceptance with a proportional increase in students learning process in terms of the proper transfer of knowledge for the learning objectives to be achieved.

This study aims to identify students' acceptance towards the use of the Discord application as an alternative learning medium during the Covid-19 pandemic within the framework of the Technology Acceptance Model (TAM). Furthermore, it examines abstract students' acceptance into a scientific data set that can be measured, calculated, and evaluated. After determining the significant size of the acceptance of students on the use of the Discord application, this research aims to also reveal the impact of this acceptance on teaching and learning activities in the future.

\section{Methods}

\subsection{Participants}

The main participants involved in this research are students of the Arabic Literature Department, Faculty of Letters, State University of Malang. However, students' responses from outside the university were also used, but they were not quite significant. Nevertheless, their responses were counted because this study focuses on the participant's responses and acceptance towards the use of Discord for their learning activities. Meanwhile, the variation regarding university origin, gender, and age tend to be ignored.

\subsection{Instruments}

Data were obtained using a questionnaire presented in Google Form and shared through social media and some students WhatsApp groups. The questionnaire is made simple to prevent the participants from spending a lot of time answering questions. This questionnaire consists of two parts, namely 1) the initial questions regarding participants' experiences in using the Discord application (P1-P3), and 2) the students' experience and acceptance questions regarding the use of this application for their learning activities (P4-P12). The participants were asked to answer the questions based on their experiences regarding the use of this application, especially during the pandemic. All question items and answer choices are shown in Table 1 as follows. 
Paper-Students' Acceptance of Discord as an Alternative Online Learning Media

Table 1. The questions or statements regarding participant experience and acceptance

\begin{tabular}{|c|c|}
\hline Questions & Answers \\
\hline \multicolumn{2}{|l|}{ Initial Questions } \\
\hline $\begin{array}{l}\text { [P1] Before conducting online lectures due to the Covid-19 pandemic, have } \\
\text { you ever used the Discord application before? }\end{array}$ & Yes, I have, No, I never have. \\
\hline $\begin{array}{l}\mathrm{P} 2] \text { If yes, what did you use the application for? } \\
\text { *Choose an answer that highly represents your habits in using this applica- } \\
\text { tion }\end{array}$ & $\begin{array}{l}\text { Team-Speak/Gaming, Discus- } \\
\text { sion Group, Learning, Chat- } \\
\text { ting, Others (if any) }\end{array}$ \\
\hline $\begin{array}{l}\text { [P3] If you have not used it before, how was your initial experience using } \\
\text { the Discord app? } \\
\text { *Choose an answer that highly represents your experience }\end{array}$ & $\begin{array}{c}\text { Fun, Excited, Boring, } \\
\text { Weird/Confused, Compli- } \\
\text { cated/Difficult, Others (if any) }\end{array}$ \\
\hline \multicolumn{2}{|l|}{ Experience and Acceptance } \\
\hline $\begin{array}{l}\text { [P4] From the design or user interface, the Discord application is quite at- } \\
\text { tractive }\end{array}$ & \multirow{9}{*}{$\begin{array}{l}\text { Strongly agree (5), Agree (4), } \\
\text { Neutral (3), Disagree (2), } \\
\text { Strongly Disagree (1) }\end{array}$} \\
\hline $\begin{array}{l}\text { [P5] The features presented in this application, such as voice channels, } \\
\text { video conferences, text messages, and share screens, are relatively com- } \\
\text { plete. }\end{array}$ & \\
\hline $\begin{array}{l}\text { [P6] I had no real difficulties installing the Discord on my smartphone or } \\
\text { laptop, and in utilizing the web version }\end{array}$ & \\
\hline $\begin{array}{l}\text { [P7] I had no difficulty using this application, even though this is my first } \\
\text { time using it as a learning media. }\end{array}$ & \\
\hline [P8] Using the Discord for learning is a fun experience & \\
\hline $\begin{array}{l}\text { [P9] Using the Discord application for online-synchronous learning ena- } \\
\text { bles users to save more on Internet quota usage compared to Zoom or } \\
\text { Google Meet. }\end{array}$ & \\
\hline $\begin{array}{l}\text { [P10] With a fast and stable Internet connection, using Discord with } \\
\text { online-synchronous learning is more fun than using Zoom or Google } \\
\text { Meet. }\end{array}$ & \\
\hline $\begin{array}{l}\text { [P11] In general, the Discord application can be used as a good alternative } \\
\text { learning media. }\end{array}$ & \\
\hline $\begin{array}{l}\text { [P12] If next semester's lecture is still being implemented in online mode, } \\
\text { would you agree on using the Discord application as an alternative learn- } \\
\text { ing media? }\end{array}$ & \\
\hline
\end{tabular}

\subsection{Analysis}

In the data analysis process, the authors did not strictly enforce statistical measures by mapping the variation of responses from participants in very detailed illustrations. This is because this is qualitative research that tries to describe and explain students' perception and acceptance of Discord as an alternative online learning media during the pandemic. Furthermore, the Likert scale of 1-5 points representing strongly disagrees (1) to strongly agree (5) is relied upon to determine the participant's acceptance towards this application for online learning purposes. The acceptance score ranges from 9-45 points, therefore an increase in the score obtained indicates a rise in the level of agreement. With this scale, participants were asked to complete the questionnaire by indicating their level of agreement with a series of questions [35][36][37]. Furthermore, Cronbach's alpha was also employed to measure the reliability of this questionnaire 
[38][39][40][41]. This coefficient was used to calculate the questionnaire (P4-P12) acceptance and ability to reach a good reliability rate of 0.883 [40].

The ground theory was also used in the analysis stage to explain and propose a new concept related to the gamification of the Discord. It was also used to determine the ability to use this application as an alternative learning media based on students' acceptance in the technology acceptance model (TAM) framework. This approach is a type of social research methodology that emphasizes on the process of generating knowledge and constructing theoretical claims in an inductive or generative way. It starts by collecting data, then elaborating and generating them to compose a research inquiry [42][43][44]. This methodology underlines the use of inductive reasoning, which involves generalizations based on observed behavior in a specific case. Therefore, by identifying students' acceptance regarding the usefulness and the ease-of-use offered by Discord as well as by exploring its gamification process, this application is expected to assist the learning activity as a good and reliable online 1 media. The students' acceptance of technology in learning activities is directly proposed in accordance with the results of their educational success.

\section{$3 \quad$ Findings}

A total of 44 students participated in filling out the questionnaire used to carry out this research. This amount is relatively small in terms of quantity. However, this research focuses on qualitative data, therefore the quality collected is irrelevant. The participants consisted of 42 students from the Arabic Literature Department at Universitas Negeri Malang, and 1 each from the Architects Department at LIKMI School of Business and IT, and the Indonesian Language Education Department at Budi Luhur University. The dominance of participants from Universitas Negeri Malang is because the authors are from the same institution.

The variation of the participants is not sufficiently distributed, therefore, it was not considered in the findings and analysis process. This is because it does not represent the respective groups of variables. The most considered findings in this research are related to students' experiences and acceptance regarding the use of the Discord application as an alternative online learning media, especially during the pandemic.

Based on the answers towards P1 regarding the use of the Discord application before the implementation of the online learning policy, it was found that 26 participants (59.09\%) had never used this application. In contrast, the remaining 18 (40.91\%) have initially used it for various activities. This response illustrated that most students are not familiar with the Discord application, especially those that have never played any games from online platforms such as Valve, Steam, Riot, etc. According to participants' answers towards P2, Discord is commonly used for team-speak when playing online games (44.44\%), while the rest is for attending lectures (38.89\%) and discussion groups $(16.67 \%)$. The summary chart of these findings is shown in Figure. 1 and 2. 


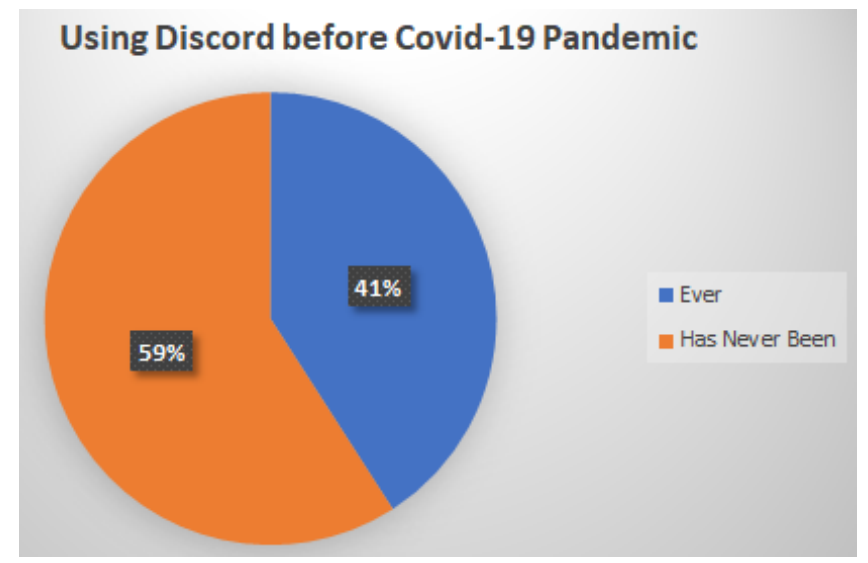

Fig. 1. Percentage of students using the Discord before online learning policy during the Covid-19 pandemic.

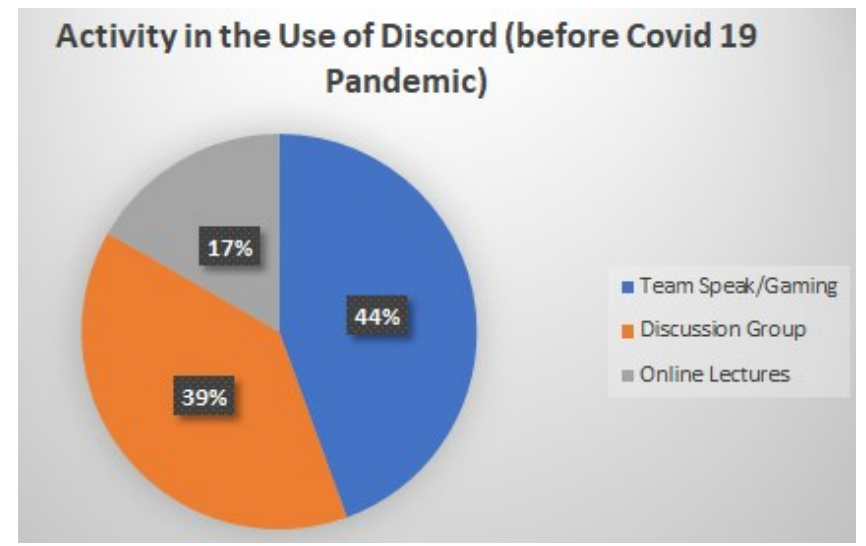

Fig. 2. Discord usage activities (before the Covid-19 pandemic)

The P3 question was used to determine the initial experience of participants using Discord for the first time. Approximately 57.69\% (15) of the participants stated that they felt strange, complicated, and confused when using the application for the first time. This is because the interface is quite complicated for beginners and unfamiliar to students that have never interacted with other users in online games. In addition, these students are more comfortable using other applications that are relatively familiar for synchronous online interaction, such as Zoom, Google Meet, WhatsApp, etc. Conversely, 9 participants (34.62\%) stated that using Discord was an interesting and enjoyable experience. Meanwhile, the remaining $2(7.69 \%)$ stated that it was not a special experience for them rather, it was indifferent with other applications. Even for the first time, those interested in using this application are students with high curiosity and are eager to learn something new. The summary of these findings is shown in Figure 3. 


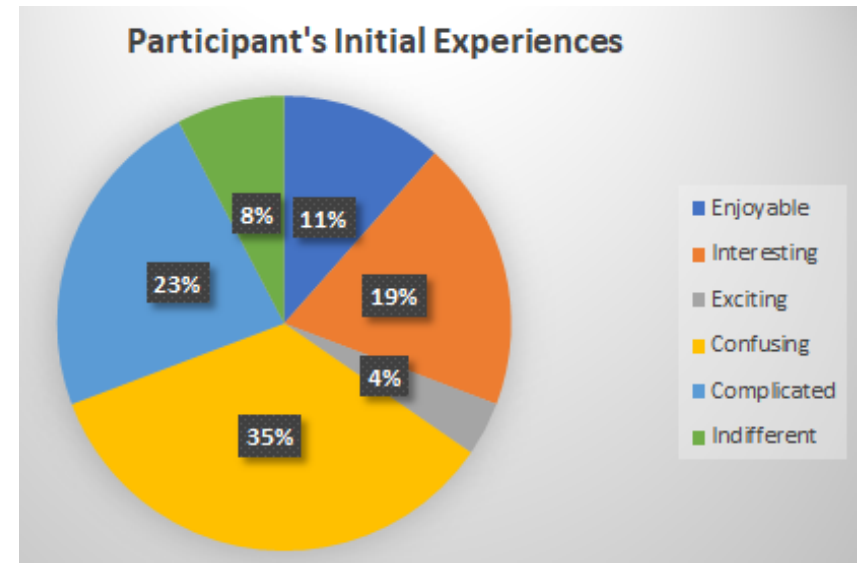

Fig. 3. Participant's initial experiences in using Discord

The Technology Acceptance Model (TAM) framework introduced by Davis [27] was used to determine students' acceptance regarding the Discord application. However, not all variables determined in this model were used to carry out this research. Moreover, there are some necessary simplifications. Therefore, the questions arranged in the questionnaire are not too incriminating. The variables represented in the P4-P12 questions are sufficient to explore students' acceptance of this application. Furthermore, students' impressions of the Discord application within the TAM framework are divided into two perceptions, namely (2) the perceived usefulness (PU) and (2) the perceived ease-of-use (PEOU). PU-related questions were expressed in P5, P9, P11, and P12, while in PEOU were in P4, P6, P7, P8, and P10, as shown in Figure 4.

Percentage (\%) of Agree Responses

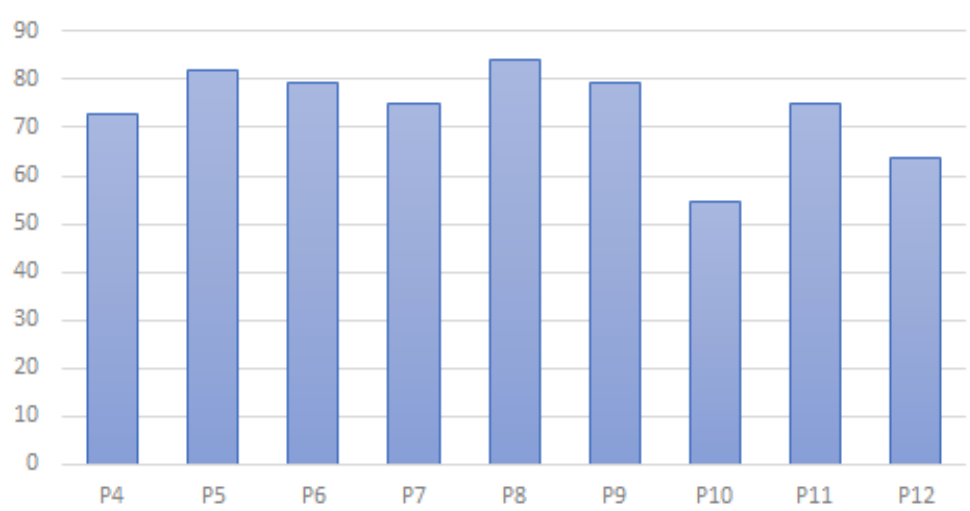

Fig. 4. Participants agree (and strongly agree) responses to P4-P12 questions 
Table 2. Explanation of figure 4:

\begin{tabular}{|l|l|}
\hline$[\mathrm{P} 4]$ & The user interface is attractive (PEOU) \\
\hline$[\mathrm{P} 5]$ & The features presented are complete and capable of supporting learning activities (PU) \\
\hline$[\mathrm{P} 6]$ & $\begin{array}{l}\text { Have no trouble when installing the application on the device or opening it in the Web } \\
\text { version (PEOU) }\end{array}$ \\
\hline$[\mathrm{P} 7]$ & $\begin{array}{l}\text { Have no difficulty using the application on the device or opening it in the Web version de- } \\
\text { spite being a first-timer (PEOU) }\end{array}$ \\
\hline$[\mathrm{P} 8]$ & It was a new and exciting experience (PEOU) \\
\hline$[\mathrm{P} 9]$ & Save more on internet quota usage compared to other video conferencing applications (PU) \\
\hline$[\mathrm{P} 10]$ & Learning becomes more interesting and fun (PEOU) \\
\hline$[\mathrm{P} 11]$ & One of the good online learning media alternatives (PU) \\
\hline$[\mathrm{P} 12]$ & Willing to use Discord in the next semester (PU) \\
\hline
\end{tabular}

Students' acceptance towards the use of this application as an alternative online learning media is measured with a Likert scale of 1-5 (strongly disagree to strongly agree). This analysis is based on their responses to P4-P12 on the distributed questionnaire. The result shows that the average point obtained from each participant's response towards the P4-P12 question is 34.86, ranging from $18-44(\mathrm{SD}=5.56)$ with a maximum gain to 45 points. Supposing it is converted to the percentage, the result becomes 34.86 / $45 * 100=77.47 \%$, indicating a good level of their agreement towards P4-P12 questions. Furthermore, when specified from the percentage of agree and strongly agree' responses to the P4-P12, participants' average response was $73.98 \%$, with the lowest and highest percentages of $54.5 \%(\mathrm{P} 10)$ and $84.1 \%(\mathrm{P} 8)$. A detailed explanation of each response to the $\mathrm{P} 4-\mathrm{P} 12$ is shared in the discussion section.

\section{Discussion}

\subsection{Students' Experience in Using Discord}

Based on the answers obtained towards the P1, most of the participants have never used Discord. Some have heard of this application without using it, as opposed to others. Therefore, Discord does not appear to be a familiar communication application for most students that compare it with WhatsApp, Line, Telegram, Zoom, Google Meet, etc. This is quite reasonable because it was originally developed for online gaming purposes, especially for the team-speak [16][17][45]. The students that have never played online games from well-known platforms like Valve, Steam, or Riot, have no idea on the use of the Discord application. However, not all players use it because some online games have in-game voice chats.

Therefore, it is not surprising that most of the participants that have used this application before the pandemic used it for the team-speak when playing online games. Meanwhile, the rest of them used it for online learning and group discussion, based on their response to the P2. This is easy to conclude because the Discord application is identical to the online gaming environment [49][50], therefore anyone that uses it is inseparable from gaming activities. 
Furthermore, those that used the Discord application for the first time were further asked to describe their initial experiences through the P3. As presented in the findings, the result showed that 15 of the 26 participants felt strange, complicated, and confused during their first trial. This is understandable because it has a different user interface compared to other applications. The user interface is quite complicated for beginners, and it seems unfamiliar to students that have never interacted with others in online games. In addition, they are more comfortable using other applications such as Zoom, Google Meet, or WhatsApp for their synchronous online learning [10][11]. In addition, there are several features in this Discord application not found in other online communication platforms. Examples are 'Text Channel' and 'Voice Channel', which functions as text group and voice communication, respectively [46][51][52]. In summary, Discord is a combined function of chat applications such as WhatsApp as communication between group members and Google Meet or Zoom as a virtual discussion platform used to share screens.

\subsection{Student's acceptance of the discord as a learning media}

Perceived of Usefulness (PU). The students' acceptance regarding the usefulness of the Discord as an alternative online learning media, is measured through their responses towards the P5, P9, P11, and P12 questions. Their responses were calculated, interpreted, and compared with the facts related to the context of the use of Discord to support learning activities.

The students' agreed responses regarding the P5 reached $81.8 \%$, thereby indicating a good perception of the usefulness of this application because it has features capable of supporting their learning objectives [25][48][50]. The main features of this application capable of assisting online learning activity are the Voice and Text Channels. Instructors are able to join and control discussions on chat groups through the creation of one or more specific topics in the Text Channel [25]. This function is similar to the breakout room feature provided by Zoom. However, the Text Channels on Discord are accessible to students without being activated by a host or instructor. Meanwhile, students are able to communicate verbally through the Voice Channel and by using the built-in microphone available on the device or by an external one. This feature is not only limited to voice chat rather it can also be used for video calls and share screens which are the common features in video conference applications. Therefore, comparing this illustration with students' responses regarding the P5 showed that they agree with using this application to support their learning activities.

In addition, based on students' responses concerning the P9, Discord is more efficient in consuming internet quota than other video conferencing applications such as Zoom and Google Meet. Sharma [51] and Cardos [52] stated that Discord had established itself as a well-developed, known and respected application for years, whereas Zoom is laggy and unpleasant. According to them, it is better than zoom in every way and has many more features, such as servers and text chats with better organization. However, the thrift of this internet quota is because most users rarely turn on their camera because this application is intended for voice chat activity when discussing gameplay strategies. As previously stated in the introduction, one of the biggest problems 
experienced by students in online learning during this Covid-19 pandemic is the large use of Internet quota. Therefore, the tendency of Discord users to maximize the text and voice chat on this application has an impact on saving Internet quota usage, thereby making it very useful in saving their monthly expenses.

Based on the students' responses to P5 and P9, Discord is a nice alternative to online learning media. This statement was also confirmed with the P11 responses by $75 \%$ of the students regarding the feasibility of this application. This feasibility lies in the completeness of features and efficiency in the use of Internet quotas. These positive affirmations led them to agree that Discord needs to be applied as a learning medium in the next semester. This explication is supported by the evidence of their agreed response to the P12, which reached $63.7 \%$. It was an insignificant gain, which sufficiently reflected the perception of the majority.

Perceived of Ease of Use (PEOU). The acceptance of participants towards the ease of use of the Discord as an alternative online learning medium is measured through students' responses to the $\mathrm{P} 4, \mathrm{P} 6, \mathrm{P} 7, \mathrm{P} 8$, and $\mathrm{P} 10$ questions. The average percentage that agreed to these questions is $72.27 \%$. This shows that they have a good perception of this application's easiness, attractiveness, and simplicity as an alternative online learning media. Furthermore, based on the response towards the P3 regarding students' initial experience in using the application, the majority still feel strange and confused at the beginning. This is shown in their responses to the questions on ease of access and use.

Based on their response to the $\mathrm{P} 4,72 \%$ of the participants gave positive affirmation that Discord has an attractive user interface. It displays all the features needed to manage various servers and the types of communication desired by the users, either through text or voice channels, which makes it interesting and exciting to use [48][49]. Indeed, some novice users feel quite confused and difficult because it has an unfamiliar interface like other common video conference applications [11][12]. However, they get used to using it and feel attracted to their new experience with the time.

One of the attributes that act as a center of attraction is the application's ability to combine features commonly used for communication purposes in learning activities such as group chats and video conferencing. Many instructors use multiple applications, which seems to make communication between them and students overlap. These features have been incorporated into an application, thereby making it easy to share information and hold virtual classes either with voice or video.

Based on the participants' responses towards the P6 and P7 questions regarding the ease of installation and use, $79.5 \%$ and $75 \%$ agreed that installing and using this application was quite easy. This application is simple to be accessed because it can be opened on almost all platforms or operating systems such as Windows, Linux, Android, macOS, IOS, and a web browser without having to install it on a specific device [17][18][23][45][49]. This ease of installation and use made the students feel comfortable installing this application on their gadgets and using it for learning activities.

Furthermore, students' positive perception of the ease and simplicity of installing and utilizing this application indicates that Discord is reasonable and highly recommended as a nice alternative online learning media. This is also supported by positive 
affirmations obtained from students' responses to P8 (84.1\%) and P10 (54.5\%), which are related to enjoyable experiences and make learning activities more enjoyable.

Students that have used Discord in their online gaming activities are likely not to have difficulty in using this application as an alternative communication medium in learning activities. They tend to feel happy because the relaxed atmosphere while playing games or chatting with their friends is carried away in their learning activities. However, some of them also don't agree because they are dedicated to the use of this application for playing games only. A significant number also use avatars as a representation of their user profile.

\section{Conclusion}

In conclusion, this study has shown that Discord, which was originally intended for gaming purposes, was accepted by students as an alternative learning media during the pandemic, even though their acceptance rate is not greatly high. Therefore, it is concluded that Discord is an interesting alternative that is easy and simple to use and does not require a large Internet quota, because it does not require the use of conventional video conferencing applications, such as Zoom or Google Meet.

However, an in-depth analysis showed that students' rejection of using the application depends on external factors. These include the availability of the Internet connection, supported devices, and their motivation to learn during the pandemic [53][54][55]. Many instructors are still using multiple applications, which leads to an overlap in communication between them and students. However, Discord combine features commonly used for communication purposes in learning activities such as group chats and video conferencing into one application. Meanwhile, there are several limitations associated with distributing the questionnaire to the participants, both in terms of university origin, gender, age, etc. Notwithstanding these limitations, the study suggests that considering this variable may lead to new findings that are more specific and accurate. In addition, the questionnaire prepared was still very simple and deemed insufficient to represent all aspects of the Technology Acceptance Model framework.

\section{Acknowledgment}

The authors are grateful to the Department of Arabic Literature, Faculty of Letters, State University of Malang, for their financial assistance in the publication of this article.

\section{$7 \quad$ References}

[1] Baloch, S., Baloch, M. A., Zheng, T., \& Pei, X. (2020). The Coronavirus Disease 2019 (COVID-19) Pandemic. The Tohoku journal of experimental medicine, 250(4), 271-278. https://doi.org/10.1620/tjem.250.271 
[2] Kamal, M. M. (2020). The triple-edged sword of COVID-19: understanding the use of digital technologies and the impact of productive, disruptive, and destructive nature of the pandemic. Information systems management, 37 (4), 310-317. https://doi.org/10.1080/ 10580530.2020 .1820634

[3] Indrajit, R. E., \& Wibawa, B. (2020, November). Portrait of Higher Education in The Covid19 Period in A Digital Literacy Perspective: A Reflection on The Online Lecture Process Experience. In 2020 Fifth International Conference on Informatics and Computing (ICIC) (pp. 1-5). IEEE. https://doi.org/10.1109/icic50835.2020.9288555

[4] Zenkov, K., Helmsing, M., Parker, A. K., Glaser, H., \& Bean, M. (2021). Portrait of the Teacher Educator as a Weary Pedagogue: Narrating our Way to a Post-Pandemic Vision of Educator Preparation. The Teacher Educators' Journal, 106.

[5] Mustajab, Duta, et al. (2020). "Working from Home Phenomenon as an Effort to Prevent COVID-19 Attacks and Its Impact on Work Productivity" in The Internasional Journal of Applied Business Volume 4 Number 1, April 2020 (https://e-journal.unair.ac.id/TIJAB/ article/view/18574)

[6] Carnevale, J. B., \& Hatak, I. (2020). Employee adjustment and well-being in the era of COVID-19: Implications for human resource management. Journal of Business Research, 116, 183-187. https://doi.org/10.1016/j.jbusres.2020.05.037

[7] Hanafi, Y., Taufiq, A., Saefi, M., Ikhsan, M. A., Diyana, T. N., Thoriquttyas, T., \& Anam, F. K. (2021). The new identity of Indonesian Islamic boarding schools in the "new normal": the education leadership response to COVID-19. Heliyon, 7(3), e06549. https://doi.org/ 10.1016/j.heliyon.2021.e06549

[8] Adedoyin, O. B., \& Soykan, E. (2020). Covid-19 pandemic and online learning: the challenges and opportunities. Interactive Learning Environments, 1-13. https://doi.org/10.1080/ 10494820.2020 .1813180

[9] Dhawan, S. (2020). Online Learning: A Panacea in the Time of COVID-19 Crisis. Journal of Educational Technology Systems, 49(1), 5-22. https://doi.org/10.1177/0047239 $\underline{520934018}$

[10] Syauqi, K., Munadi, S., \& Triyono, M. B. (2020). Students' Perceptions toward Vocational Education on Online Learning during the COVID-19 Pandemic. International Journal of Evaluation and Research in Education, 9(4), 881-886. https://doi.org/10.11591/ijere. v9i4.20766

[11] Azlan, C. A., Wong, J. H. D., Tan, L. K., Huri, M. S. N. A., Ung, N. M., Pallath, V., ... \& $\mathrm{Ng}, \mathrm{K}$. H. (2020). Teaching and learning of postgraduate medical physics using Internetbased e-learning during the COVID-19 pandemic-A case study from Malaysia. Physica Medica, 80, 10-16. https://doi.org/10.1016/j.ejmp.2020.10.002

[12] Ahmadi, A., \& Ilmiani, A. M. (2020). The Use of Teaching Media in Arabic Language Teaching During Covid-19 Pandemic. Dinamika Ilmu, 20(2), 307-322. https://doi.org/10. 21093/di.v20i2.2515

[13] Shisley, S. (2020). Emergency remote learning compared to online learning. Learning Solutions. Retrieved from https://learningsolutionsmag.com/articles/emergency-remote-learning-compared-to-online-learning (accessed on 24th June, 2021)

[14] Malelak, E. O., Taneo, J., \& Ufi, D. T. (2021). Problems of Online Learning During The Covid-19 Pandemic in Generation Z. Paedagoria: Jurnal Kajian, Penelitian dan Pengembangan Kependidikan, 12(1), 115-121. https://doi.org/10.31764/paedagoria.v12i1.4044

[15] Berrada K. et al. (2021) From the Paper Textbook to the Online Screen: A Smart Strategy to Survive as an Online Learner. In: Burgos D., Tlili A., Tabacco A. (eds) Radical Solutions for Education in a Crisis Context. Lecture Notes in Educational Technology. Springer, Singapore. https://doi.org/10.1007/978-981-15-7869-4_13 
[16] Skains, Lyle. (2010). Teaching on Discord, retrieved from Medium. Link: https://medium. com/@1skains/teaching-on-discord-a96b510986b (accessed on January 6 $6^{\text {th, }}$ 2021)

[17] Ravel, Kristin. (2020). Discord: Gaming App to Rhetoric Class, retrieved from DRC: Digital Rhetoric Collaborative. Retrieved from: https://www.digitalrhetoriccollaborative.org/ 2020/08/03/discord-gaming-app-to-rhetoric-class/ (accessed on January 6th, 2021)

[18] Razell, Liam. (2020). Students use Discord to stay connected during the pandemic, retrieved from Martlet: The University of Victoria's Independent Newspaper. Link: https://www. martlet.ca/lifestyle-discord-uvic-2020/ (accessed on January $5^{\text {th, } 2020)}$

[19] Kalogiannakis, M., Papadakis, S., \& Zourmpakis, A. I. (2021). Gamification in Science Education. A Systematic Review of the Literature. Education Sciences, 11(1), 22. https://doi.org/10.3390/educsci11010022

[20] Papadakis S., Kalogiannakis M. (2018) Using Gamification for Supporting an Introductory Programming Course. The Case of ClassCraft in a Secondary Education Classroom. In: Brooks A., Brooks E., Vidakis N. (eds) Interactivity, Game Creation, Design, Learning, and Innovation. ArtsIT 2017, DLI 2017. Lecture Notes of the Institute for Computer Sciences, Social Informatics and Telecommunications Engineering, vol 229. Springer, Cham. https://doi.org/10.1007/978-3-319-76908-0 35

[21] Prott, D., \& Ebner, M. (2020). The Use of Gamification in Gastronomic Questionnaires. International Journal of Interactive Mobile Technologies, 14(2). https://doi.org/10. 3991/ijim.v14i02.11695

[22] Wulanjani, A. N. (2018). Discord Application: Turning a Voice Chat Application for Gamers into a Virtual Listening Class. In English Language and Literature International Conference (ELLiC) Proceedings (Vol. 2, pp. 115-119)

[23] Cacho, J.F. (2020). "Using Discord to Improve Student Communication, Engagement, and Performance". UNLV Best Teaching Practices Expo. 95. https://digitalscholarship.unlv. edu/btp expo/95

[24] Jiang, J. A., Kiene, C., Middler, S., Brubaker, J. R., \& Fiesler, C. (2019). Moderation challenges in voice-based online communities on Discord. Proceedings of the ACM on HumanComputer Interaction, 3(CSCW), 1-23. https://doi.org/10.1145/3359157

[25] Lacher, Lisa \& Biehl, Cydnee. (2018). Using Discord to Understand and Moderate Collaboration and Teamwork: (Abstract Only), in Proceedings of the 49th ACM Technical Symposium on Computer Science Education (SIGCSE 18). Association for Computing Machinery, New York, NY, USA, 1107. https://doi.org/10.1145/3159450.3162231

[26] Kruglyk, V., Bukreiev, D., Chornyi, P., Kupchak, E., \& Sender, A. (2020). Discord platform as an online learning environment for emergencies. Ukrainian Journal of Educational Studies and Information Technology, 8(2), 13-28. https://doi.org/10.32919/uesit. 2020.02.02

[27] Davis, F.D. (1989). "Perceived Usefulness, Perceived Ease of Use, and User Acceptance of Information Technology," MIS Q., vol. 13, no. 3, pp. 319-340. https://doi.org/10.2307/ $\underline{249008}$

[28] Fishbein, M. \& Ajzen, I. (1975). Belief, attitude, intention, and behavior: an introduction to theory and research. Reading, Mass: Addison-Wesley Pub. Co

[29] Liu, X. (2010). "Empirical Testing of a Theoretical Extension of the Technology Acceptance Model: An Exploratory Study of Educational Wikis," Commun. Educ., vol. 59, no. 1, pp. 52-69. https://doi.org/10.1080/03634520903431745

[30] Papadakis, St. (2020). Robots and Robotics Kits for Early Childhood and First School Age. International Journal of Interactive Mobile Technologies (iJIM), 14 (18), 34-56. https://doi.org/10.3991/ijim.v14i18.16631 
[31] Su, A. Y., Yang, S. J., Hwang, W. Y., \& Zhang, J. (2010). A Web 2.0-based collaborative annotation system for enhancing knowledge sharing in collaborative learning environments. Computers \& Education, 55(2), 752-766. https://doi.org/10.1016/j.compedu.2010.03.008

[32] Larmuseau, C., Desmet, P., \& Depaepe, F. (2019). Perceptions of instructional quality: Impact on acceptance and use of an online learning environment. Interactive Learning Environments, 27(7), 953-964. https://doi.org/10.1080/10494820.2018.1509874

[33] Chung, C., \& Ackerman, D. (2015). Student reactions to classroom management technology: Learning styles and attitudes toward Moodle. Journal of Education for Business, 90(4), 217-223. https://doi.org/10.1080/08832323.2015.1019818

[34] Al-Maroof, R. S., Salloum, S. A., AlHamadand, A. Q. M., \& Shaalan, K. (2020). Understanding an Extension Technology Acceptance Model of Google Translation: A Multi-Cultural Study in United Arab Emirates. International Journal of Interactive Mobile Technologies, (3). https://doi.org/10.3991/ijim.v14i03.11110

[35] Likert, R. (1932). A Technique for the Measurement of Attitudes. Archives of Psychology, 22 140, 55. https://legacy.voteview.com/pdf/Likert 1932.pdf

[36] Boone, H.N., Boone D.A. (2012). Analyzing Likert Data, in Journal of Extension Volume 50 Number 2 https://joe.org/joe/2012april/pdf/JOE v50 2tt2.pdf

[37] Joshi, A., Kale, S., Chandel, S., Pal, D.K. (2015). Likert Scale: Explored and Explained, in British Journal of Applied Science \& Technology, ISSN: 2231-0843, Vol.: 7, Issue.: 4 https://doi.org/10.9734/BJAST/2015/14975

[38] Cronbach, Lee J. (1990). Essentials of Psychological Testing. 5th edition. New York: Harper Collins

[39] Bryman, A. \& Bell, E. (2007). Business Research Methods. New York: Oxford University Press.

[40] Taber, K.S. (2018). “The Use of Cronbach's Alpha When Developing and Reporting Research Instruments in Science Education”. Research in Science Education 48, 1273-1296 (2018). https://doi.org/10.1007/s11165-016-9602-2

[41] Bonett, D.G. \& Wright, T.A. (2014). "Cronbach's alpha reliability: Interval estimation, hypothesis testing, and sample size planning", in Journal of Organizational Behaviour Vol 36 Issue 1 https://doi.org/10.1002/job.1960

[42] Glaser, B.G. \& Strauss, A.L. (2006). Discovery of Grounded Theory: Strategies for Qualitative Research. Aldine Transaction

[43] Charmaz, Kathy. (2006). Constructing Grounded Theory: A Practical Guide through Qualitative Analysis. London: SAGE Publications Ltd. https://doi.org/10.7748/nr.13.4.84.s4

[44] Urquhart, Cathy. (2013). Grounded Theory for Qualitative Research: A Practical Guide. London: SAGE Publications Ltd.

[45] Hinduja, Sameer. (2018). Discord: A Chat App Not Just for Gamers, retrieved from Cyberbullying Research Centre. Link: https://cyberbullying.org/discord-chat-app-gamers (accessed on January 6th, 2021)

[46] Motyliński, M., MacDermott, Á., Iqbal, F., Hussain, M., \& Aleem, S. (2020). Digital forensic acquisition and analysis of discord applications. In 2020 International Conference on Communications, Computing, Cybersecurity, and Informatics (CCCI) (pp. 1-7). IEEE. https://doi.org/10.1109/ccci49893.2020.9256668

[47] Minor, Jordan. (2020). What Is Discord and How Do You Use It? PCMag. Retrieved from https://sea.pcmag.com/how-to-work-from-home/37330/what-is-discord-and-how-do-youuse-it (accessed on 15 ${ }^{\text {th }}$ July, 2021). https://doi.org/10.1002/9781119450962.ch6

[48] Lacher, L. L., \& Biehl, C. (2019). Investigating Team Effectiveness Using Discord: A Case Study Using a Gaming Collaboration Tool for the CS Classroom. Int'l Conf. Frontiers in 
Education: $C S$ and CE | FECS'19 |. https://csce.ucmss.com/cr/books/2019/LFS/CSRE A2019/FEC2450.pdf

[49] Morris, T. (2020). Discord for Dummies. John Wiley \& Sons.

[50] Rosen, Amanda. (2020). What tools are we using? And why Discord should be one of them., retrieved from Active Learning and in Political Science. Link: https://activelearningps.com/2020/03/17/what-tools-are-we-using-and-why-discord-should-be-one-of-them/ (accessed on February $8^{\text {th, }}$ 2021). https://doi.org/10.1111/ejn.15025/v1/review1

[51] Sharma, A. (2020). Discord VS Zoom., retrieved from The Hatched. Link: https:// thewhshatchet.org/discord-vs-zoom/ (accessed on 10th February 2021)

[52] Cardos, Nat. (2020). Is Discord competition for Zoom in online learning? retrieved from Coast Report Online. Link: https://www.coastreportonline.com/features/article 42c512b40e95-11eb-ad5c-9b9cba66d39b.html (accessed on February 10th, 2021)

[53] Aguilera-Hermida, A. P. (2020). College students' use and acceptance of emergency online learning due to COVID-19. International Journal of Educational Research Open, 1, 100011. https://doi.org/10.1016/j.ijedro.2020.100011

[54] Gonzalez-Ramirez, J., Mulqueen, K., Zealand, R., Silverstein, S., Mulqueen, C., \& BuShell, S. (2021). Emergency Online Learning: College Students' Perceptions During the COVID19 Pandemic. College Student Journal, 55(1), 29-46. https://doi.org/10.2139/ssrn.3831526

[55] Zaccoletti, S., Camacho, A., Correia, N., Aguiar, C., Mason, L., Alves, R. A., \& Daniel, J. R. (2020). Parents' perceptions of student academic motivation during the COVID-19 lockdown: A cross-country comparison. Frontiers in psychology, 11. https://doi.org/ $\underline{10.3389 / \text { fpsyg. } 2020.592670}$

\section{Authors}

Muhammad Lukman Arifianto is a lecturer in Arabic Department, Faculty of Letters, Universitas Negeri Malang, Indonesia. His main research interest is grammar and linguistics; both theoretical and applied. Since becoming a lecturer, he is also interested in researching about teaching and learning.

Iqbal Fathi Izzudin is a student in Arabic Department, Faculty of Letters, Universitas Negeri Malang, Indonesia. His main research interest is in the history of Arabic and Arabic linguistics. He can be contacted via Email: iqfadin11@gmail.com.

Article submitted 2021-03-26. Resubmitted 2021-08-09. Final acceptance 2021-08-09. Final version published as submitted by the authors. 